\title{
A new role for tamoxifen in oestrogen receptor-negative breast cancer when it is combined with epigallocatechin gallate
}

\author{
MJ Scandlyn', EC Stuart', TJ Somers-Edgar', AR Menzies' and RJ Rosengren*,I \\ 'Department of Pharmacology and Toxicology, University of Otago, Dunedin, New Zealand
}

We have previously shown that tamoxifen + epigallocatechin gallate (EGCG) is synergistically cytotoxic towards oestrogen receptor (ER)-negative breast cancer cells. To determine if this response would correlate with significant tumour suppression in vivo, athymic nude female mice were implanted with MDA-MB-23I cells and treated with tamoxifen, EGCG, EGCG + tamoxifen, or vehicle control for 10 weeks. Tumour volume in EGCG- $\left(25 \mathrm{mg} \mathrm{kg}^{-1}\right)+$ tamoxifen $\left(75 \mu \mathrm{gg}^{-1}\right)$-treated mice decreased by $71 \%$ as compared with vehicle control $(P<0.05)$, whereas tumour weight was decreased by $80 \%$ compared with control $(P<0.01)$. Epigallocatechin gallate treatment did not alter ER protein expression in MDA-MB-23। cells and thus was not a mechanism for the observed tumour suppression. However, western blotting of tumour extracts demonstrated that epidermal growth factor receptor (EGFR; 85\% lower than control), pEGFR (78\% lower than control), mammalian target of rapamycin (mTOR; 78\% lower than control), and CYPIBI (75\% lower than control) were significantly lower after the combination treatment as compared with all other treatments. Nuclear factor- $\kappa \mathrm{B}(\mathrm{NF}-\kappa \mathrm{B})$, b-Raf, p-MEK, S6K, 4EBPI, Akt, vascular EGFR-I (VEGFR-I) and VEGF expressions were decreased in control but not in the individual treatments, whereas MEK, phospholipase D I/2, TGF $\alpha$, and ERK expressions were not changed after any treatment. The results demonstrate that tamoxifen at realistic doses $\left(75 \mu \mathrm{g} \mathrm{kg}^{-1}\right)$ can suppress the growth of ERnegative breast cancer when combined with EGCG. In addition, the dominant mechanism for tumour suppression is the concomitant decrease in tumour protein expressions of $m T O R$ and the EGFR.

British Journal of Cancer (2008) 99, I056- 1063. doi:I0.1038/sj.bjc.6604634 www.bjcancer.com

Published online 16 September 2008

(c) 2008 Cancer Research UK

Keywords: EGCG; tamoxifen; MDA-MB-23I; CYPIBI; mTOR; EGFR

Tamoxifen has been extensively used in the treatment of oestrogen receptor (ER)-positive breast cancer and was recently approved for chemoprevention in high-risk women (Fisher et al, 1998, 2005). In ER-positive breast cancer, tamoxifen acts as an SERM, as it antagonises the binding of estradiol to the ER. However, tamoxifen is not a highly selective drug and it elicits pro-apoptotic effects in ER-negative breast cancer cells by the modulation of various cell signalling proteins in an ER-independent manner (Fattman et al, 1998; Ferlini et al, 1999; Mandlekar et al, 2000). However, these effects have generally been reported following relatively high concentrations of tamoxifen. An appealing strategy would be to use tamoxifen in combination with other agents to enhance its action in ER-negative breast cancer. This concept has been shown by combining docetaxel, genistein, black cohosh, and palm oil tocotrienols (Ferlini et al, 1997; Guthrie et al, 1997; Tanos et al, 2002; Bollig et al, 2005; Al-Akoum et al, 2007) with tamoxifen, which elicited cytotoxicity, apoptosis, and G1 arrest in various ERnegative breast cancer cell lines. Recently, this has been shown in both MDA-MB-231 cells and a xenograft model by combining tamoxifen with OSU-03012, a phosphoinositide-dependent protein kinase-1/Akt inhibitor (Weng et al, 2008). Our laboratory has also used ER-negative breast cancer cells to demonstrate that a combination of epigallocatechin gallate (EGCG) and tamoxifen

*Correspondence: Dr RJ Rosengren;

E-mail: rhonda.rosengren@stonebow.otago.ac.nz

Revised I4 August 2008; accepted 4 August 2008; published online 16 September 2008 elicits synergistic cytotoxicity (Chisholm et al, 2004). We further demonstrated that EGCG + tamoxifen elicits an earlier and enhanced apoptotic response in MDA-MB-231 cells (Stuart et al, 2007), and this correlated with a decrease in protein expression of the active form of the epidermal growth factor receptor (EGFR) after combination treatment (Stuart and Rosengren, 2007).

The EGFR is a clinically significant target for ER-negative breast cancer, as it is overexpressed in ER-negative breast cancer cells (Roos et al, 1986) as well as in patients with ER-negative breast cancer (Biswas et al, 2004). Furthermore, it is involved in cell proliferation, apoptosis, angiogenesis, tumour invasiveness, and distant metastases (Grandis and Sok, 2004). The EGFR exerts its effects on cellular function through the activation of numerous downstream signalling pathways, including the Raf-MEK-ERK mitogen-activated protein kinase pathway and the $\mathrm{PI}_{3} \mathrm{~K}-\mathrm{Akt}$ pathway (Dutta and Maity, 2007). The stimulation of the Raf-MEK-ERK cascade leads to the activation of numerous transcription factors that are important for cell proliferation and survival (Brott et al, 1993). Epidermal growth factor receptor signalling through the $\mathrm{PI}_{3} \mathrm{~K}-\mathrm{Akt}$ pathway results in the activation of the transcription factor nuclear factor- $\kappa \mathrm{B}$ (NF- $\kappa \mathrm{B}$ ) (constitutively active in ER $\alpha$ - breast cancers) and mammalian target of rapamycin (mTOR), an important regulator of protein synthesis (Averous and Proud, 2006). Recently, the importance of the dual suppression of both EGFR and mTOR expressions was shown when the proliferation of breast cancer was synergistically reduced after the inhibition of both EGFR and mTOR expressions (Buck et al, 2006). 
The aims of this study were to determine whether the tumour suppression potential of the combination of EGCG + tamoxifen in a xenograft model of ER-negative breast cancer. On the basis of our previous in vitro studies in MDA-MB-231 cells, we postulated that the inhibition of both EGFR and mTOR expressions would be important mechanisms for tumour suppression after combination treatment. Therefore, we measured EGFR and its major downstream targets in tumours to demonstrate drug-mediated effects on critical cell signalling pathways from treated mice. We also examined tumour protein expression of CYP1B1, because this protein provides a new target for the suppression of tumour growth, as it is overexpressed in many human cancers, including breast cancer (Murray et al, 1997).

\section{MATERIALS AND METHODS}

\section{Chemicals and reagents}

Epigallocatechin gallate ( $99 \%$ purity) was purchased from the Cayman Chemical Company (Ann Arbor, MI, USA). MDA-MB-231 human breast cancer cells were purchased from ATCC (Manassas, VA, USA). Matrigel and the primary antibodies Akt, pAkt, EGFR, pEGFR and CYP1B1 were purchased from BD Biosciences (Auckland, New Zealand). Minimum essential medium, potassium chloride, $\mathrm{NaHCO}_{3}, \mathrm{NaCl}$, trizma hydrochloride, Triton X-100, trypsin, and trypan blue were purchased from Sigma Chemical Co. (St Louis, MO, USA). Acetic acid, disodium hydrogen orthophosphate anhydrous, EDTA, DMSO, potassium dihydrogen orthophosphate, and sodium citrate were purchased from $\mathrm{BDH}$ Laboratory supplies (Poole, UK). Primary antibodies NF- $\kappa \mathrm{B}$, bRaf, $\mathrm{TGF} \alpha$, 4EBP1, p4EBP1, vascular endothelial growth factor receptor (VEGF), VEGFR-1, mTOR, PLD1, PLD2, S6K, pS6K, MEK, pMEK, ERK, pERK, ER $\alpha$, and $\mathrm{ER} \beta$ were purchased from Abcam (Cambridge, MA, USA). Foetal bovine serum was purchased from Life Technologies Ltd. (Auckland, New Zealand). All other chemicals were the highest purity commercially available.

\section{Cell culture}

MDA-MB-231 and MCF-7 cells were maintained in minimum essential medium supplemented with $10 \%$ foetal bovine serum, $1 \%$ antibiotic/antimitotic solution, and $0.2 \% \mathrm{NaHCO}_{3}$. Cells were cultured in $75 \mathrm{~cm}^{2}$ flasks and incubated in $5 \% \mathrm{CO}_{2} / 95 \%$ humidified air at $37^{\circ} \mathrm{C}$.

\section{Animals and treatment}

Female CD1 athymic nude mice (5- to 6-week old) were purchased from Hercus Taieri Resource Unit (Dunedin, New Zealand). They had free access to sterilised standard Reliance Rodent Diet (Dunedin, New Zealand) and water, and were housed four mice per cage and maintained at $21-24^{\circ} \mathrm{C}$ with a 12 -h light/dark cycle in a specifically designed pathogen-free isolation facility and allowed to acclimatise for 1 week before experimentation. The University of Otago Animal Ethics Committee approved all procedures. Mice were inoculated into the right flank with ER-negative cells (MDAMB-231, $2 \times 10^{6} / 50 \mu \mathrm{l}$ matrigel), which were left to form palpable tumours. Tumour volume was measured weekly with electronic calipers (L W H). When the tumour volume reached $100 \mathrm{~mm}^{3}$, mice (10 per group) were randomly assigned to the various treatment groups. Mice were then treated daily with tamoxifen (50 or $\left.75 \mu \mathrm{g} \mathrm{kg}^{-1}\right)$, EGCG $\left(25 \mathrm{mg} \mathrm{kg}^{-1}\right), \mathrm{EGCG}+$ tamoxifen, or a vehicle control for each drug $\left(5 \mathrm{ml} \mathrm{kg}^{-1}\right)$ for 10 weeks. Dosing solutions were prepared fresh each day. Tamoxifen was given through oral gavage, whereas EGCG was given intraperitoneally. On the account of extensive first-pass metabolism ( $\mathrm{Li}$ et al, 2001), EGCG is often administered parentally (Liao et al, 1995; Landis-Piwowar et al, 2007; Somers-Edgar et al, 2008). In addition, the dose of EGCG
( $25 \mathrm{mg} \mathrm{kg}^{-1}$, i.p.) was based on our previous study, which demonstrated that this dose was non-toxic and elicited a modest decrease in MDA-MB-231 tumour growth (Somers-Edgar et al, 2008). This dose is also twofold lower than that recently used in other ER-negative xenograft experiments with EGCG (Landis-Piwowar et al, 2007; Thangapazham et al, 2007). On the basis of our in vitro experiments with EGCG + tamoxifen, we wanted to use a very low dose of tamoxifen. Therefore, we chose a dose of tamoxifen that was at least 10 -fold lower than that has typically been used in other xenograft studies.

\section{Assessment of animal health}

Food consumption and body weight were monitored daily throughout the treatment period. Mice were euthanised by $\mathrm{CO}_{2}$ inhalation $24 \mathrm{~h}$ after the last dose and necropsies were then performed. Blood was collected through the inferior vena cava and placed on ice, whereas major organs, as well as tumours, were excised and weighed. Organ weights are expressed as a percentage of body weight. Plasma was separated and used to determine the presence of hepatotoxicity via the plasma marker alanine aminotransferase activity using a commercially available kit (Medica Pacifica, Auckland, New Zealand). Results are expressed as IU ${ }^{-1}$.

\section{Preparation of whole cell lysates}

MDA-MB-231 and MCF-7 cells were plated (200 000 cells per well) in six-well plates and treated for $24 \mathrm{~h}$ with EGCG $(100 \mu \mathrm{M})$ or estradiol (100 nM). Cells were harvested using a cell scraper, washed, and incubated in RIPA buffer (50 mM Tris base, 1\% NP-40, $0.25 \%$ sodium deoxycolate, $100 \mathrm{~mm}$ sodium chloride, $1 \mathrm{~mm}$ EDTA, and complete protease inhibitor cocktail tablets; Roche, Mannheim, Germany), incubated on ice for $15 \mathrm{~min}$, and centrifuged at 13000 r.p.m. for $10 \mathrm{~min}$ at $4^{\circ} \mathrm{C}$. The supernatant was collected and the protein concentration was determined using the BCA assay.

\section{Western blotting of proteins from cell lysates or tumour extracts}

Protein extraction from tumour tissue was performed as described (Somers-Edgar et al, 2008). The extracts or cell lysates were fractioned by SDS-PAGE, electrotransferred to nitrocellulose membranes, blotted with each antibody, and detected by amplified colour reagent (Bio-Rad, Auckland, New Zealand). $\beta$-Actin was used as a loading control, and the density of each band was normalised to the $\beta$-actin control. For clarity in the figures, densitometry is shown only for proteins that were modulated by drug treatment.

\section{Immunohistochemistry of tumour sections}

Tumours were embedded in OCT compound and then sectioned $(5 \mu \mathrm{m})$, fixed in acetone, and air-dried overnight. Sections were then washed twice in Tween 20-PBS, incubated with normal serum for $30 \mathrm{~min}$ at room temperature, and then incubated overnight with primary CYP1B1 or VEGFR-1 antibody. Slides were then rinsed and peroxidase blocked using hydrogen peroxide (3\%) before incubation with the appropriate secondary antibody for $30 \mathrm{~min}$ at room temperature in a humidified chamber. The sections were then incubated with ExtrAvidin (Bio-Rad, Auckland, New Zealand) $(1: 20)$ for $30 \mathrm{~min}$ at room temperature in a humidified chamber before development with 3,3'-diaminobenzidine tetrahydrochloride as the chromogen and counterstaining with Mayer's haematoxylin. Once slides were dehydrated, DPX mounting medium and coverslips were applied. The sections were analysed from tumours obtained from each mouse and a representative slide is shown in the results section. 


\section{Statistical analysis}

For all parameters where the variances were significantly different between control and treated mice (namely, tumour volume and tumour weight), the data were log-transformed before statistical analysis was performed. Tumour growth experiments were analysed using a repeated measures two-way ANOVA coupled with a Student-Newman-Keuls post hoc test, in which $P<0.05$ was the minimum requirement for a statistically significant difference. Analyses that did not involve time (i.e., tumour weight and protein expression) were analysed using an one-way ANOVA coupled with a Student-Newman-Keuls post hoc test, in which $P<0.05$ was the minimum requirement for a statistically significant difference.

\section{RESULTS}

\section{The combination of EGCG and tamoxifen suppresses tumour growth in vivo}

When EGCG $\left(25 \mathrm{mg} \mathrm{kg}^{-1}\right)$ was combined with tamoxifen $\left(50 \mu \mathrm{g} \mathrm{kg}^{-1}\right)$, the growth rate of the tumours in the combination treated mice lagged behind the other treatments, but an overall significant decrease in tumour growth was not observed (Figure 1A). A significant decrease in tumour growth was observed when the dose of tamoxifen in combination with EGCG was increased to $75 \mu \mathrm{g} \mathrm{kg}^{-1}$. Specifically, after 6 weeks of treatment, the growth curve from the combination treated mice diverged from other treatments (Figure 1B). After 10 weeks of treatment, the combination treated mice had a tumour volume that was $71.3 \%$ smaller than both the vehicle- and tamoxifen-treated mice $(P<0.05)$. Tumour weight was also decreased significantly after combination treatment (tumour weights of $0.45 \pm 0.08,0.45 \pm 0.14$, $0.29 \pm 0.4$ and $0.09 \pm 0.2 \mathrm{~g}$ for vehicle, tamoxifen, EGCG and EGCG + tamoxifen, respectively) (Figure 1C). Importantly, the drug treatments were well tolerated and non-toxic to the mice, as weight gain and all other physiological parameters (i.e., liver, kidney, spleen and uterine weight) were in the normal range (data not shown) and no hepatotoxicity was observed as alanine aminotransferase activity was not elevated following any of the drug treatments (values ranged between 23 and $27 \mathrm{IU}^{-1}$ ).

\section{EGCG does not reverse the ER status of MDA-MB-231 breast cancer cells}

As EGCG has upregulated ER $\alpha$ expression in cell lines with a low $\mathrm{ER} \alpha$ expression (Belguise et al, 2007), it was necessary to determine whether the tumour suppression could be due to an EGCG-mediated change in the protein expression of the ER in MDA-MB-231 cells. Therefore, MDA-MB-231 cells were treated with EGCG $(100 \mu \mathrm{M})$ or estradiol $(100 \mathrm{nM})$ for $24 \mathrm{~h}$, and MCF-7 cells were treated with estradiol $(100 \mathrm{nM})$ as a control. The results demonstrated that estradiol increased the protein expression of both ER $\alpha$ and ER $\beta$ in MCF-7 cells, whereas neither EGCG nor estradiol induced the protein expression of the ER in MDA-MB231 cells (Figure 2).

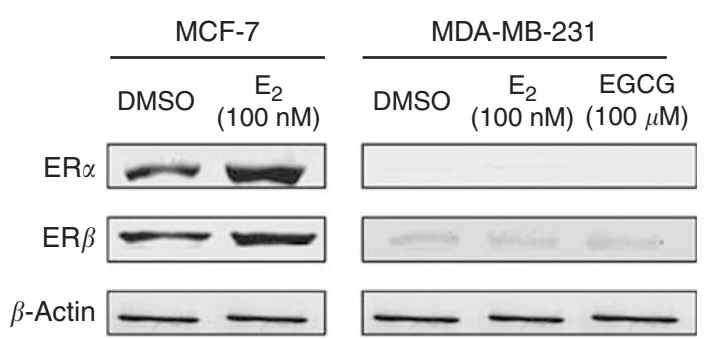

Figure 2 Protein expressions of $\mathrm{ER} \alpha$ and $\mathrm{ER} \beta$ in MCF-7 and MDA-MB23 I cells. Cells were treated with $100 \mathrm{nM}$ of estradiol $\left(\mathrm{E}_{2}\right)$ or with $100 \mu \mathrm{M}$ of EGCG for $24 \mathrm{~h}$. The blots shown are representative of three independent experiments performed in duplicate.
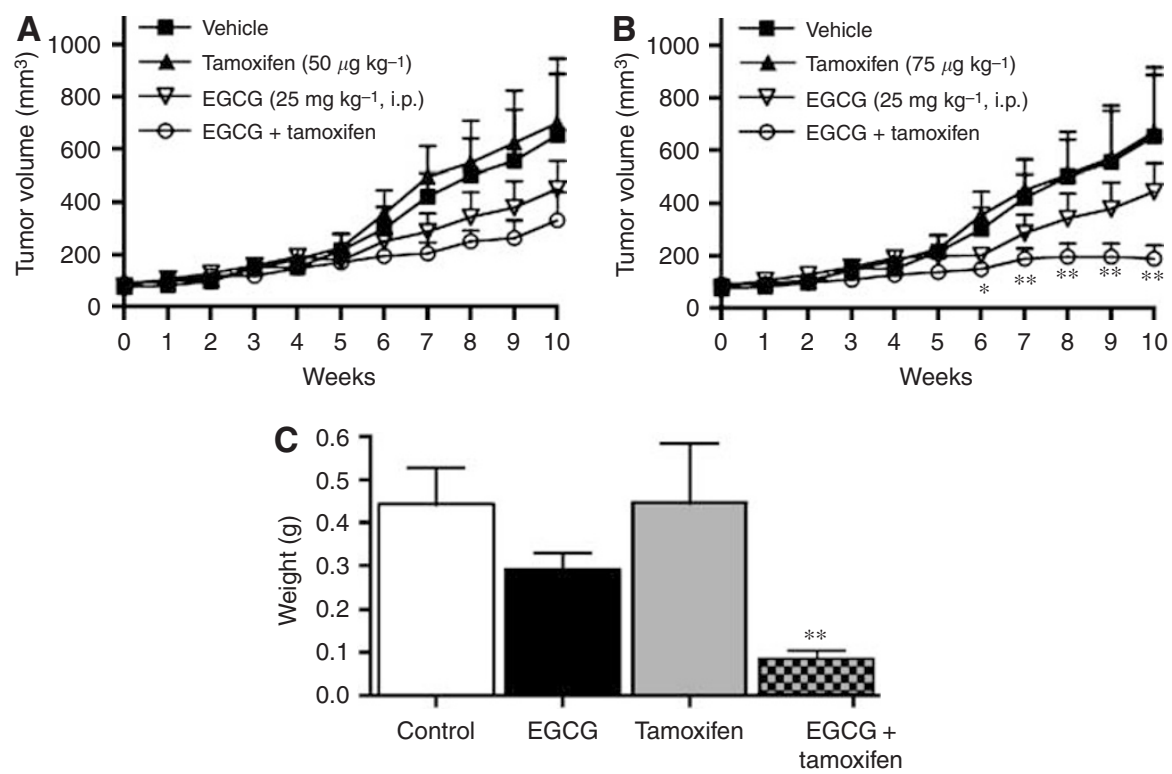

Figure I Tumour growth after the treatment with EGCG and tamoxifen. Female athymic nude mice were implanted with MDA-MB-23। cells $\left(2 \times 10^{6}\right)$ and treated for 70 days. (A) Tumour volume during the treatment with vehicle $\left(5 \mathrm{ml} \mathrm{kg}^{-1}\right)$, EGCG $\left(25 \mathrm{mg} \mathrm{kg}^{-1}\right.$, i.p.), tamoxifen (50 $\mu$ g kg ${ }^{-1}$, p.o.), or EGCG + tamoxifen. (B) The tumour volume during treatment with vehicle $\left(5 \mathrm{ml} \mathrm{kg}^{-1}\right)$, EGCG $\left(25 \mathrm{mg} \mathrm{kg}\right.$, i.p.), tamoxifen (75 $\mu$ g kg ${ }^{-1}$, p.o.), or EGCG + tamoxifen. (C) Tumour weight after 70 days of treatment with EGCG $\left(25 \mathrm{mg} \mathrm{kg}^{-1}\right.$, i.p.) and tamoxifen $\left(75 \mu \mathrm{g} \mathrm{kg}{ }^{-1}\right.$, p.o.). Symbols and bars represent the mean \pm s.e.m. from 10 mice per group. $*$ Combination treatment significantly different from vehicle control $(P<0.05)$. $* * C o m b i n a t i o n$ treatment significantly different from all other groups $(P<0.05)$. 
The combination of EGCG and tamoxifen regulates EGFR and $\mathrm{mTOR}$ in vivo

As we have previously shown that EGCG +4 -OHT produces an earlier and greater apoptotic response (Stuart et al, 2007) and elicits a greater inhibition of pEGFR in MDA-MB-231 cells (Stuart and Rosengren, 2007), the role of the EGFR and other downstream cell signalling proteins were determined in tumour extracts. The results showed that the protein expression of EGFR was significantly decreased in tumours from combination-treated mice as compared with all other treatments (relative density of EGFR in the EGCG + tamoxifen group was decreased by $85.3 \pm 3.33$, $76.0 \pm 5.5$ and $71.2 \pm 6.6 \%$ as compared with control, EGCG, and tamoxifen, respectively, $P<0.001$ ) (Figure $3 \mathrm{~A}$ and $\mathrm{B}$ ). A similar trend was also observed for the active form of EGFR pEGFR (relative density of pEGFR in the EGCG + tamoxifen group was decreased by $78.4 \pm 5.3,71.2 \pm 7.0$ and $61.0 \pm 9.6 \%$ as compared with control, tamoxifen, and EGCG, respectively, $P<0.001$ ) (Figure $3 \mathrm{~A}$ and $\mathrm{B}$ ). However, TGF $\alpha$, a regulator of EGFR signalling, was not changed following any of the treatments (Figure 3A). Given that the combination of EGCG + tamoxifen significantly reduced levels of both EGFR and pEGFR, downstream targets of this receptor were examined. As the EGFR signals predominantly through the mitogen-activated protein kinase cascade and the $\mathrm{PI}_{3} \mathrm{~K}-\mathrm{Akt}$ pathways, components of these pathways were investigated. Protein expression of the mitogen-activated protein kinase cascade members MEK, ERK, and pERK were unchanged following any of the treatments (Figure 3A). However, combination treatment caused tumour protein levels of the ERK regulator pMEK to decrease by $76.6 \pm 5.3 \%$ as compared with vehicle control $(P<0.05)$ (Figure $3 \mathrm{~A}$ and $\mathrm{B})$. Other downstream targets measured (Akt, NF- $\kappa \mathrm{B}$, and b-Raf) in tumours from combination-

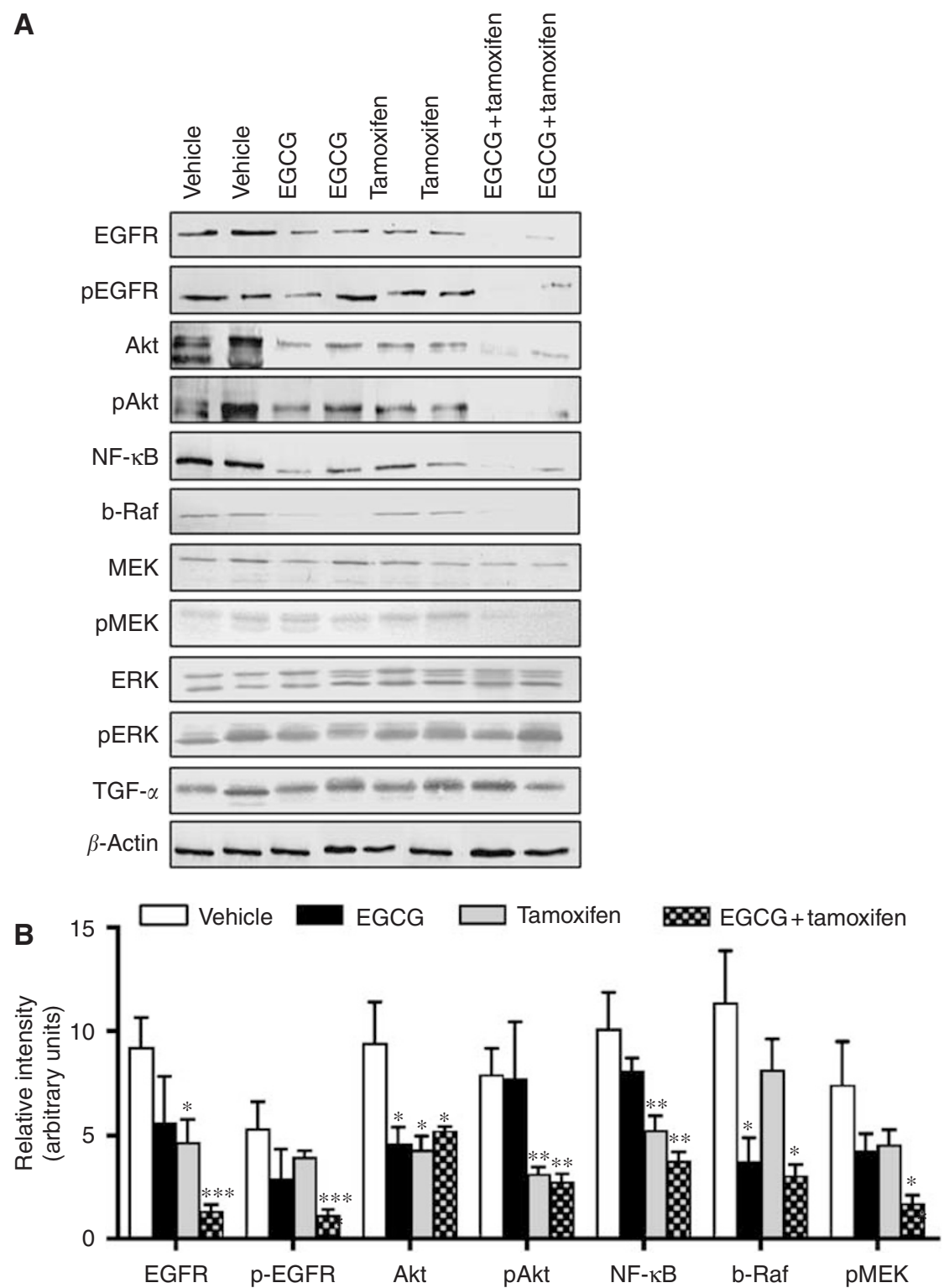

Figure 3 Tumour protein expression levels of EGFR, Akt, NF- $\kappa \mathrm{B}$, b-Raf, ERK and MEK after treatment with EGCG and tamoxifen. Mice were treated with vehicle $\left(5 \mathrm{ml} \mathrm{kg}^{-1}\right)$, EGCG $\left(25 \mathrm{mg} \mathrm{kg}^{-1}\right.$, i.p.), tamoxifen $\left(75 \mu \mathrm{g} \mathrm{kg}{ }^{-1}\right.$, p.o.), or EGCG + tamoxifen for 70 days. (A) Representative western blots of the various proteins from each individual mouse. (B) The results of scanning densitometry of western blots. For clarity, densitometry is shown only for proteins that were modulated by drug treatment. Bars represent the mean \pm s.e.m. from 10 mice per group. *Significantly different from vehicle control $(P<0.05)$. ***ignificantly different from vehicle and EGCG $(P<0.0 \mathrm{I})$. ***3ignificantly different from all other treatments $(P<000 \mathrm{I})$. 
treated mice were all significantly decreased in control, whereas p-Akt and NF- $\kappa \mathrm{B}$ were also decreased in control and EGCG (Figure $3 \mathrm{~A}$ and $\mathrm{B}$ ).

As $\mathrm{mTOR}$ is a major regulator of protein translation and other processes important in cell proliferation, this protein as well as its targets, S6K and 4EBP1 were also examined in tumour extracts. The results demonstrated that protein expression of mTOR and S6K were significantly decreased in tumours from combination treatment mice as compared with all other treatment groups (relative density of mTOR was decreased by 78.0 $\pm 6.9,78.4 \pm 6.8$ and $80.0 \pm 6.3 \%$ as compared with control, tamoxifen, and EGCG, respectively, $P<0.001$ ) (Figure $4 \mathrm{~A}$ and $\mathrm{B}$ ). However, $\mathrm{pS6 \textrm {K }}$ was not changed following any of the treatments, whereas both 4EBP1 and p4EBP1 were decreased in control but not in the individual treatments (Figure 4A and B). Phospholipase D (PLD) 1 and 2 represent an alternate upstream regulator of mTOR. However, the protein expression of these isoforms was not altered by any of the treatments (Figure 4A).

\section{The combination of EGCG and tamoxifen regulates VEGF, VEGFR-1, and CYP1B1 in vivo}

The tumour marker CYP1B1 was also decreased by $71.5 \%$ in tumour tissue from combination-treated mice as compared with

A
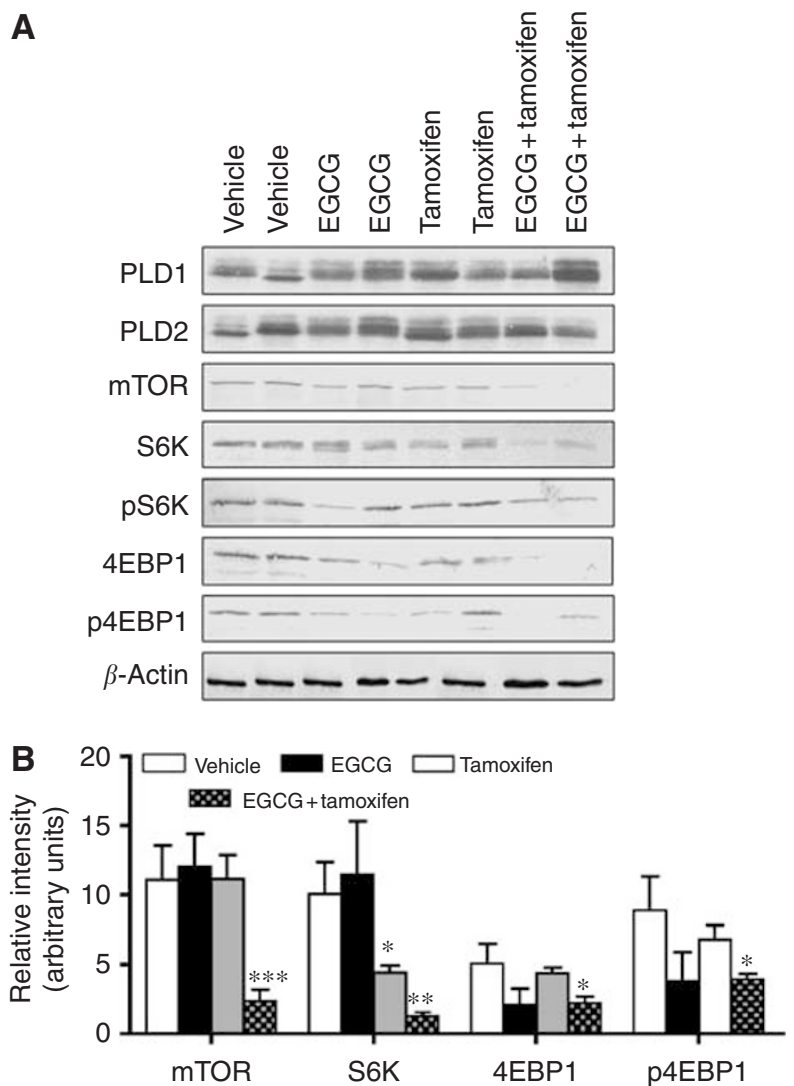

Figure 4 Tumour protein expression levels of mTOR, S6K and 4EBP I after treatment with EGCG and tamoxifen. Mice were treated with vehicle $\left(5 \mathrm{ml} \mathrm{kg}^{-1}\right)$, EGCG (25 mg kg${ }^{-1}$, i.p.), tamoxifen $\left(75 \mu \mathrm{kg}^{-1}\right.$, p.o.), or EGCG + tamoxifen for 70 days. (A) Representative western blots of the various proteins from each individual mouse. (B) The results of scanning densitometry of western blots. For clarity, densitometry is shown only for proteins that were modulated by drug treatment. Bars represent the mean \pm s.e.m. from 10 mice per group. *Significantly different from vehicle control $(P<0.05)$. **Significantly different from vehicle and EGCG $(P<0.0 \mathrm{I})$. ****Significantly different to all other treatments $(P<000 \mathrm{I})$. vehicle control as shown by western blotting and immunohistochemistry (Figure $5 \mathrm{~A}-\mathrm{C}$ ). This protein was also decreased as compared with each single drug treatment (relative intensities of $1.98 \pm 0.42,4.47 \pm 0.48$, and $5.88 \pm 1.69$ for EGCG + tamoxifen, tamoxifen, and EGCG, respectively, $P<0.05)$. To gain insight into the role of angiogenesis in the growing tumour, VEGF, an important regulator of angiogenesis (Sledge, 2002), which also aids in breast cancer cell survival (Wu et al, 2006), was examined in tumour extracts. All treatments decreased both VEGF and its receptor VEGFR-1 approximately 50\% from control as shown by both western blotting and immunohistochemistry (Figure $5 \mathrm{~A}-\mathrm{C}$ ), but this effect was not enhanced after combination treatment.

\section{DISCUSSION}

We have shown that the combination of tamoxifen $\left(75 \mu \mathrm{g} \mathrm{kg}^{-1}\right.$, p.o.) and EGCG (25 mg kg, i.p.) inhibits the growth of MDA-MB231 xenografts and that this effect is superior to that elicited by either individual treatment. Another study has shown that the combination of green tea extract $(2.5 \mathrm{~g} / \mathrm{l})$ and tamoxifen $(20 \mathrm{mg}$ pellet) is better than either drug alone at suppressing the growth of MCF-7 xenografts, and this correlated with increased levels of apoptosis and a suppression of angiogenesis in tumour tissue (Sartippour et al, 2006). However, this drug combination has not previously been examined in an in vivo model of ER-negative breast cancer.

Our results demonstrated that tamoxifen on its own was not effective at suppressing ER-negative tumour growth, whereas EGCG had a modest effect on tumour growth, but the combination of the two drugs showed marked tumour suppression. Other studies have also shown that EGCG or green tea extract has a modest inhibitory effect on ER-negative tumour growth (Landis-Piwowar et al, 2007; Thangapazham et al, 2007; Somers-Edgar et al, 2008). For example, EGCG $\left(50 \mathrm{mg} \mathrm{kg}^{-1}\right.$, s.c.) was minimally effective at reducing tumour growth in a MDA-MB231 xenograft model, but acetylating EGCG and thus turning it into a pro-drug enhanced its efficacy (Landis-Piwowar et al, 2007). In a similar xenograft model, the efficacy of EGCG was increased by the addition of curcumin (Somers-Edgar et al, 2008). However, the overall tumour volume was only decreased by $49 \%$ as compared with control after EGCG + curcumin treatment, indicating that EGCG + tamoxifen is a more effective combination therapy as tumour volume was decreased by $71 \%$ as compared with control. Another recent study has shown that ER-negative breast cancer cells can be sensitised to the effects of tamoxifen by using a PDK-1/ Akt inhibitor (Weng et al, 2008). In this study, tamoxifen $\left(60 \mathrm{mg} \mathrm{kg}^{-1}\right)$ was unable to suppress the growth of MDA-MB-231 xenografts, but the addition of OUS- $03012\left(100 \mathrm{mg} \mathrm{kg}^{-1}\right)$ showed significant tumour suppression (decreased $50 \%$ in control). This result supports the use of tamoxifen in combination therapies for ER-negative breast cancer. However, our combination with EGCG produced a greater level of tumour suppression at a much lower dose of tamoxifen $\left(75 \mu \mathrm{g} \mathrm{kg}^{-1}\right)$.

The mechanism responsible for the enhanced tumour suppression and apoptosis (Stuart et al, 2007) elicited by EGCG + tamoxifen does not involve EGCG-mediated changes in the ER status of MDA-MB-231 cells. Furthermore, when the ER is present, tamoxifen acts to antagonise the effects of estradiol, and as our model does not involve the use of estradiol pellets, there is no ER-mediated response to antagonise. Instead, the mechanism is most likely to be initiated by the modulation of EGFR activity. Our results demonstrate that both protein levels of EGFR and its active phosphorylated form are significantly reduced by EGCG + tamoxifen treatment. Although there was no further reduction in the active form of EGFR after combination treatment, the similar decrease in both the unphosphorylated and 
A

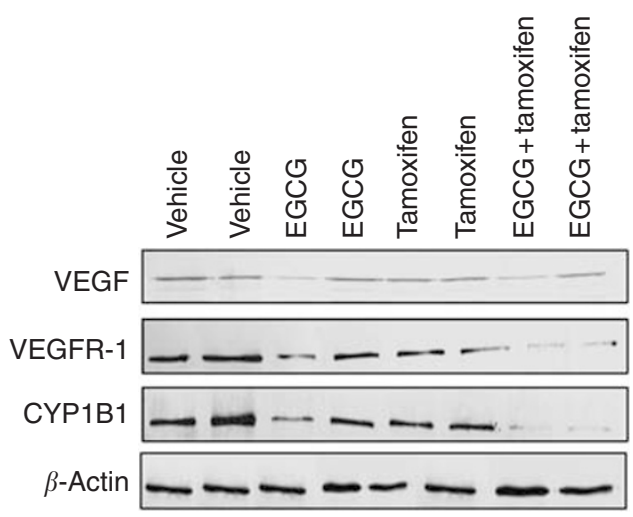

B

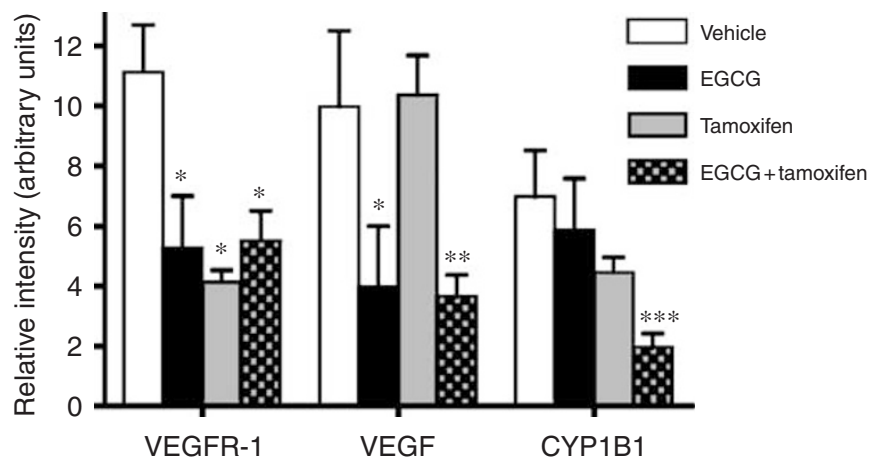

C

C

E

$T$

$E+T$

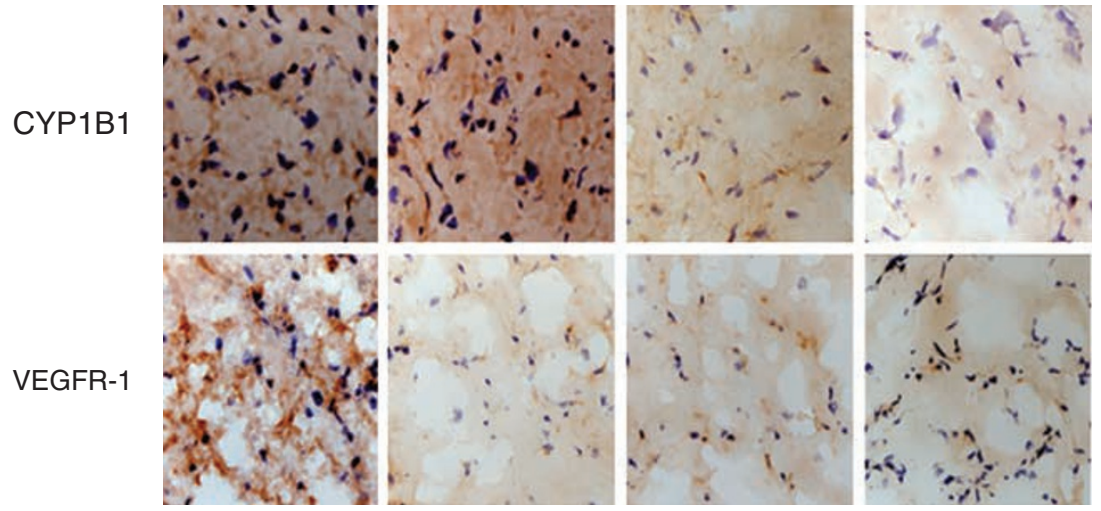

Figure 5 Tumour protein expression levels of VEGF, VEGFR-I, and CYPIBI after treatment with EGCG and tamoxifen. Mice were treated with vehicle $\left(5 \mathrm{ml} \mathrm{kg}^{-1}\right)$, EGCG $\left(25 \mathrm{mg} \mathrm{kg}^{-1}\right.$, i.p.), tamoxifen $\left(75 \mu \mathrm{g} \mathrm{kg}^{-1}\right.$, p.o.), or EGCG + tamoxifen for 70 days. (A) Representative western blots of the various proteins from each individual mouse. (B) The results of scanning densitometry of western blots. For clarity, densitometry is shown only for proteins that were modulated by drug treatment. Bars represent the mean \pm s.e.m. from 10 mice per group. (C) Representative immunohistochemistry of CYPIBI and VEGFR-I from tumour sections of treated mice. *Significantly different from vehicle control $(P<0.05)$. **Significantly different from vehicle and tamoxifen $(P<0.0 \mathrm{I})$. **** Significantly different from all other treatments $(P<000 \mathrm{I})$.

phosphorylated forms indicates that the signalling capacity of the pathway as a whole was reduced by approximately $78 \%$ by the combination treatment. Combination treatment also caused a similar reduction in the protein expression of mTOR. The inhibition of mTOR is of particular significance, as this is a key regulator of protein synthesis within the cell. Furthermore, the growth of renal cell carcinoma (Gemmill et al, 2005), glioblastoma multiforme (Goudar et al, 2005), as well as non-small-cell lung cancer, pancreatic, colon, and breast (Buck et al, 2006) cancers were synergistically reduced when EGFR inhibitors were combined with the mTOR inhibitor rapamycin. The in vitro results correlated with synergistic tumour suppression in a xenograft model of nonsmall-cell lung cancer. Interestingly, the results showed neither of the individual drugs significantly suppressed tumour growth, but showed pronounced reduction after combination treatment. Our results are very similar, in that pronounced reduction in tumour growth only occurred after EGCG + tamoxifen. As a similar $(\sim 80 \%)$ and significant reduction of EGFR and mTOR occurred after combination therapy, it is most likely that this dual suppression is a key mechanistic component of the observed tumour suppression. Furthermore, the decreased expression of mTOR is not likely to be regulated further upstream through PLD1/2, as levels of PLD1 and PLD2 were not altered by any drug treatments. However, the combined inhibition of EGFR, Akt, and mTOR after EGCG + tamoxifen treatment provides a powerful suppression of tumour growth. 
Studies with EGCG in a variety of models have demonstrated that it decreases angiogenesis (Cao and Cao, 1999; Sartippour et al, 2001, 2002). Our results support this, as tumour-derived VEGF was decreased after EGCG treatment. Therefore, the inhibition of VEGF after combination treatment appears to be mediated by EGCG, and thus the inhibition of tumour-derived VEGF is not a mechanism for the combination treatment. However, VEGF and VEGFR-1 levels in the surrounding mouse stromal tissue would provide additional information regarding the overall effect of the drug treatment on angiogenesis.

Another important effect elicited by the drug combination is the $78 \%$ decrease in the protein expression of CYP1B1. CYP1B1 has not been examined previously following the in vivo administration of EGCG. However, this protein could be important in ER-negative breast cancer, as the CYP1B1_1358_A $>$ G polymorphism has been significantly associated with ER-negatvie tumour status (Justenhoven et al, 2008). This genotype is known to encode higher CYP1B1 activity and it is believed to contribute to low levels of the ER in these tumours by a reduction in estradiol. As EGCG has been shown to modulate CYP1B1 in MCF-7 cells (Guengerich et al, 2003) and antagonise AhR-mediated responses (Palermo et al, 2005), our results of decreased CYP1B1 protein expression after combination treatment is not surprising. The role of CYP1B1 in tumour suppression was also shown in a study where CYP1B1 null mice were protected against DMBA-induced tumours as compared with their wild-type counterparts (Buters et al, 1999). As CYP1B1 can inactivate the prostate cancer dug flutamide (Rochat et al, 2001) and is also induced in breast cancer cells after treatment with docetaxel (Martinez et al, 2008), it may have an important function in the development of resistance to chemotherapy. Overall, CYP1B1 has a variety of functions in both the treatment and development of breast cancer. Therefore, the $78 \%$ inhibition of CYP1B1 elicited by EGCG + tamoxifen treatment is a critical component of its mechanism of action.

In summary, we have demonstrated that the combination of EGCG + tamoxifen significantly reduced ER-negative tumour growth and that this was driven primarily by an enhanced effect by the decreased protein expression of the EGFR, mTOR, and CYP1B1. Overall, our findings suggest that EGCG + tamoxifen as an antitumorigenic therapy in ER-negative breast cancer is promising and thus this combination warrants further investigation.

\section{ACKNOWLEDGEMENTS}

We thank Martin J Le Nedelec for his technical assistance. This work was funded by grants from the Breast Cancer Research Trust and University of Otago Faculty of Medicine Bequest Funds. University of Otago Postgraduate Scholarships were awarded to MJS, ECS, TJS-E and ARM.

\section{REFERENCES}

Al-Akoum M, Dodin S, Akoum A (2007) Synergistic cytotoxic effects of tamoxifen and black cohosh on MCF-7 and MDA-MB231 human breast cancer cells: an in vitro study. Can J Physiol Pharmacol 85: $1153-1159$

Averous J, Proud CG (2006) When translation meets transformation: the mTOR story. Oncogene 25: 6423-6435

Belguise K, Guo S, Sonenshein GE (2007) Activation of FOXO3a by the green tea polyphenol epigallocatehin-3-gallate induces estrogen receptor a expression reversing invasive phenotype of breast cancer cells. Cancer Res 67: $5763-5770$

Biswas DK, Shi Q, Baily S, Strickland I, Ghosh S, Perdee AB, Iglehart JD (2004) NF-kB activation in human breast cancer specimens and its role in cell proliferation and apoptosis. Proc Natl Acad Sci USA 101: $10137-10142$

Bollig A, Du Q-Q, Fan S-T, Yu B, Sarkar FH, Liao J (2005) Combination of 5-deoxy-5-fluorouridine and tamoxifen show cell-type specific antagonists and cooperative effects on cytotoxicity in human mammary carcinoma cells. Oncol Rep 14: $177-183$

Brott BK, Alessandrini A, Largaespada DA, Copeland NG, Jenkins NA, Crews CM, Erikson RL (1993) MEK2 is a kinase related to MEK 1 and is differentially expressed in murine tissues. Cell Growth Differ 4: $921-929$

Buck E, Eyzaguirre A, Brown E, Petti F, McCormack S, Haley JD, Iwata KK, Gibson NW, Griffin G (2006) Rapamycin synergizes with the epidermal growth factor receptor inhibitor erlotinib in non-small-cell lung, pancreatic, colon, and breast tumors. Mol Cancer Ther 5: 2676-2684

Buters JTM, Sakai S, Richter T, Pineau T, Alexander DL, Savas U, Doehmer J, Ward JM, Jefcoate CR, Gonzalez FJ (1999) Cytochrome P450 CYP1B1 determines susceptibility to 7,12-dimethylbenz[a]anthracene-induced lymphomas. Proc Natl Acad Sci USA 96: 1977-1982

Cao Y, Cao R (1999) Angiogenesis inhibited by drinking tea. Nat Med 398: 381

Chisholm K, Bray BJ, Rosengren RJ (2004) Tamoxifen and epigallocatechin gallate (EGCG) are synergistically cytotoxic to MDA-MB-231 human breast cancer cells. Anticancer Drugs 15: 889-897

Dutta PR, Maity A (2007) Cellular responses to EGFR inhibitors and their relevance to cancer therapy. Cancer Lett 254: 165-177

Fattman CL, An B, Sussman L, Dou QP (1998) p53-Independent dephosphorylation and cleavage of retinoblastoma protein during tamoxifeninduced apoptosis in human breast cancer carcinoma cells. Cancer Lett 130: $103-113$
Ferlini C, Scambia G, Distefano M, Filippinin P, Isola G, Riva A, Bombardelli E, Fattorossi A, Benedetti Panici P, Mancuso S (1997) Synergistic antiproliferative activity of tamoxifen and docetaxel on three oestrogen receptor-negative cancer cell lines is mediated by the induction of apoptosis. Br J Cancer 75: 884-891

Ferlini C, Scambia G, Marone M, Distefano M, Gaggini C, Ferrandina G, Fattorossi A, Isola G, Panici PB, Mancuso S (1999) Tamoxifen induced oxidative stress and apoptosis in estrogen receptor-negative human cancer cell lines. Br J Cancer 79: 257-263

Fisher B, Costantino JP, Wickerham DL, Redmond CK, Kavanah M, Cronin WM, Vogel V, Robidous A, Dimitrov N, Atkins J, Daly M, Wieand S, Tan-Chiu E, Ford L, Wolmark N (1998) Tamoxifen for prevention of breast cancer: report of the national Surgical Adjuvant Breast and Bowel Project P-1 Study. J Natl Cancer Inst 90: 1371-1388

Fisher B, Costantino JP, Wickerham LD, Cecchini RS, Cronin WM, Robidoux A, Bevers TB, Kavanah MT, Atkins JN, Margolese RG, Runowicz CD, James JM, Ford LG, Wolmark N (2005) Tamoxifen for the prevention of breast cancer: current status of the National Surgical Adjuvant Breast and Bowel Project P-1 Study. J Natl Cancer Inst 97: $1652-1662$

Gemmill RM, Zhou M, Costa L, Bukowski RM, Drabki HA (2005) Synergistic growth inhibition by Iressa and rapamycin is modulated by VHL mutations in renal cell carcinoma. Br J Cancer 92: 2266-2277

Goudar RK, Shi Q, Hjelmelad MD, Keir ST, McLendon RE, Wikstrand CJ, Reese ED, Conrad CA, Traxler P, Lane HA, Reardon DA, Cavenee WK, Wang X, Bigner DD, Friedman HS, Rich JN (2005) Combination therapy of inhibitors of epidermal growth factor receptor/vascular endothelial growth factor receptor 2 (AE788) and the mammalian target of rapamycin (RAD001) offers improved glioblastoma tumor inhibition. Mol Cancer Ther 4: $101-112$

Grandis JR, Sok JC (2004) Signaling through the epidermal growth factor receptor during the development of malignancy. Pharmacol Ther 102: $37-46$

Guengerich FP, Chun Y-J, Kim D, Gillam EMJ, Shimada T (2003) Cytochrome P450 1B1: a target for inhibition in anticarcinogenesis strategies. Mutat Res 523-524: 173-182

Guthrie N, Gapor A, Chambers AF, Carroll KK (1997) Inhibition of proliferation of estrogen receptor negative MDA-MB-435 and positive MCF-7 human breast cancer cells by palm oil tocotrienols and tamoxifen, alone and in combination. J Nutr 127: $544 \mathrm{~S}-548 \mathrm{~S}$ 
Justenhoven C, Pierl CB, Haas S, Fischer HP, Baisch C, Hamann U, Harth V, Pesch B, Brüning T, Vollmert C, Illig T, Dippon J, Ko YD, Brauch H (2008) The CYP1B1_1358 GG genotype is associated with estrogen receptor-negative breast cancer. Breast Cancer Res Treat 111: 171-177

Landis-Piwowar KR, Huo C, Chen D, Milacic V, Shi G, Chan TH, Dou QP (2007) A novel prodrug of the green tea polyphenol (-)-epigallocatechin-3-gallate as a potential anticancer agent. Cancer Res 67: $4303-4310$

Li C, Meng X, Winnik B, Lee MJ, Lu H, Sheng S, Zhu N, Sheng S, Buckley B, Yang CS (2001) Analysis of urinary metabolites of tea catechins by liquid chromatography/electron ionization mass spectrometry. Chem Res Toxicol 14: 702-707

Liao S, Umekita Y, Guo J, Kokontis JM, Hiipakka RA (1995) Growth inhibition and regression of human prostate and breast tumors in athymic mice by tea epigallocatechin gallate. Cancer Lett 96: 239-243

Mandlekar S, Yu R, Tan T-H, Kong A-NT (2000) Activation of caspase-3 and c-jun NH2-terminal kinase-1 signaling pathways in tamoxifeninduced apoptosis of human breast cancer cells. Cancer Res 60: $5995-6000$

Martinez VG, O'Connor R, Clynes M (2008) CYP1B1 expression is induced by docetaxel: effect on cell viability and drug resistance. $\mathrm{Br} J$ Cancer 98: $564-570$

Murray GI, Taylor MC, McFadyen MC, McKay JA, Greenlee WF, Burke MD, Melvin WT (1997) Tumor-specific expression of cytochrome P450 CYP1B1. Cancer Res 57: 3026-3031

Palermo CM, Westlake CA, Gasiewicz TA (2005) Epigallocatechin gallate inhibits aryl hydrocarbon receptor gene transcription through an indirect mechanism involving binding to a $90 \mathrm{kDa}$ heat shock protein. Biochem Biophys Res Com 44: 5041-5052

Rochat BM, Morsman JM, Murray GI, Figg WD, McLeod HL (2001) Human CYP1B1 and anticancer agent metabolism: mechanism for tumor-specific drug inactivation? J Pharmacol Exp Ther 296: 537-541

Roos W, Fabbro D, Kung W, Costa SD, Eppenberger U (1986) Correlation between hormone dependency and the regulation of epidermal growth factor receptor by tumour promoters in human mammary carcinoma cells. Proc Natl Acad Sci USA 83: 991-995

Sartippour MR, Heber D, Ma J, Lu Q, Go VL, Nguyen M (2001) Green tea and its catechins inhibit breast cancer xenografts. Nutr Cancer 40: $149-156$
Sartippour MR, Pietras R, Marquez-Garban DC, Chen H-W, Heber D, Henning SM, Sartippour G, Zhange L, Lu M, Weinberg O, Rao JY, Brooks MN (2006) The combination of green tea and tamoxifen is effective against breast cancer. Carcinogenesis 27: 2424-2433

Sartippour MR, Shao Z-M, Heber D, Beatyy P, Zhang L, Liu C, Ellis L, Liu W, Go VL, Brooks MN (2002) Green tea inhibits vascular endothelial growth factor (VEGF) induction in human breast cancer cells. J Nutr 132: $2307-2311$

Sledge GW (2002) Vascular endothelial growth factor in breast cancer: biologic and therapeutic aspects. Semin Oncol 29: 104-110

Somers-Edgar TJ, Scandlyn MJ, Stuart EC, Le Nedelec MJ, Valentine SP, Rosengren RJ (2008) The combination of epigallocatechin gallate and curcumin suppresses ERa-breast cancer cell growth in vitro and in vivo. Int J Cancer 122: 1966 - 1971

Stuart EC, Larsen L, Rosengren RJ (2007) Potential mechanisms for the synergistic cytotoxicity elicited by 4 -hydroxytamoxifen and epigallocatechin gallate in MDA-MB-231 cells. Int J Oncol 30: 1407-1412

Stuart EC, Rosengren RJ (2007) EGCG and 4-hydroxytamoxifen synergistically induced cytotoxicity in MDA-MB-231 human breast cancer cells: the role of apoptosis and signaling proteins. In American Association for Cancer Research, pp 3282. Cadmus Professional Communications: Los Angeles

Tanos V, Brzezinski A, Drize O, Strauss N, Peretz T (2002) Synergistic inhibitory effects of genistein and tamoxifen on human dysplastic and malignant epithelial breast cell in vitro. Eur J Obst Gyn Repro Biol 102: $188-194$

Thangapazham RL, Singh AK, Sharma A, Warren J, Gaddipati JP, Maheshwari RK (2007) Green tea polyphenols and its constituent epigallocatechin gallate inhibits proliferation of human breast cancer cells in vitro and in vivo. Cancer Lett 245: 232-241

Weng S-C, Kashida U, Kulp SK, Wang D, Brueggemeier RW, Shapiro C, Chen C-S (2008) Sensitizing estrogen receptor-negative breast cancer cells to tamoxifen with OSU-03012, a novel celecoxib-derived phophoinositide-dependent protein kinase-1/Akt signaling inhibitor. Mol Cancer Ther 7: $800-808$

Wu Y, Hooper AT, Zhong Z, Witte L, Bohlen P, Rafii S, Hicklin DJ (2006) The vascular endothelial growth factor receptor (VEGFR-1) supports growth and survival of human breast carcinoma. Int $J$ Cancer 119: $1519-1529$ 